\title{
Model Predictive Control of STATCOM for Grid Voltage Regulation
}

\author{
Nima Kadivarian, Mohammad Tavakoli Bina and Mohsen Akbari \\ Department of Electrical Engineering \\ K.N. Toosi University of Technology \\ Tehran (Iran) \\ e-mail: nima_kadivaryan@ymail.com, tavakoli@eetd.kntu.ac.ir, mohsen.akbari.eng@gmail.com
}

\begin{abstract}
In this paper, a predictive control method known as FS-MPC is raised to adjust the grid voltage by STATCOM. The FS-MPC control strategy is easy to implement that considers nonlinearities and limitations as well. In this way, the system model is used to predict the current behavior in the next sampling period for each possible switching mode. The STATCOM is simulated using the FS-MPC control method by MATLAB SIMULINK, and compared to conventional PI-controller accompanied with the PWM. The results of simulations represent considerable improvement in the performance of the FS-MPC control method for adjusting the grid voltage variations.
\end{abstract}

\section{Keywords}

Model predictive control; STATCOM; voltage regulation; FSMPC

\section{Introduction}

The increasing complexity of the operation and control of power electronics devices cause power systems to face new challenges. Unstable voltage (voltage fluctuation) is one of the problems that has emerged in recent years due to excessive operation and an increase in load demand. One of the most widely used methods to improve the voltage profile is the use of static compensator (STATCOM) [1],[2]. This compensator due to the flexibility and controllability is always considered by researchers.

The STATCOM can quickly and efficiently provide a reactive power to improve power system voltage fluctuations [1]. The most important part of this compensator is its control system. Power electronics semiconductors such as IGBTs are responsible for the STATCOM control. Control models such as adaptive control, conventional PI control [3], hysteresis control [4], fuzzy logic control [5], [6] and predictive model control (MPC) are used to implement in the compensator based on a digital signal process. In most of these methods a modulator scheme (such as PWM, SVM, etc.) is required to generate the gate signal for switches, and internal and external control loops are also included. In these schemes, due to the modulator, the switching frequency is fixed as well. However, the MPC is a method not including these rules and is easy to implement.
In the MPC, the switching frequency is not fixed and because of the absence of a modulator the gate signal is directly commanded from the controller block [7],[8]. The most important advantages of this method are putting limitations and nonlinear problems, as well as not being limited to a control variable. It means that several variables can be controlled, but one of the most important problems is high computation load in a very short sampling time, to solve optimization problems in converters. To overcome this problem two solutions are raised: solving optimization problems as offline [9], and computations optimize by evaluating all of the switching states. In this paper, the latter is introduced and studied as entitled FS-MPC for the STATCOM control system [10], [11].

The novelty of this paper is application of FS-MPC controller instead of conventional PI-PWM controller in STATCOM. In the new control method compared to conventional PI control, the current harmonics and ripples of the STATCOM is lower and also the FS-MPC structure is simpler due to lack of modulator and also PI gains are not necessary to determine as a result of lack of PI controller. In this paper, two control methods i.e. FS-MPC and PI-PWM are well compared to control the distribution network voltage via STATCOM.

The paper structure is as follows: in the second part, a general description is presented for the STATCOM. In the third part, a finite state-MPC (FS-MPC) control method is studied, and in next part the simulation results of FS-MPC controller is presented and compared to the conventional PI-PWM controller on a $20 \mathrm{kV}$ grid. Finally, a conclusion is given.

\section{Static Compensator (STATCOM)}

As seen in Fig. 1, the STATCOM is composed of three main parts: a power inverter, a set of reactors connected to an isolated transformer and a control system [1], [12].

As it has been said, the most important part of the STATCOM is the control system to compensate and improve the reactive power and voltage of the power system, and usually consists of two parts [1]: internal control loop and external control loop. The reference current signals are calculated by the external control loop 
with the desired target. The reference currents are generated using the PI control loops as shown in Fig. 2.

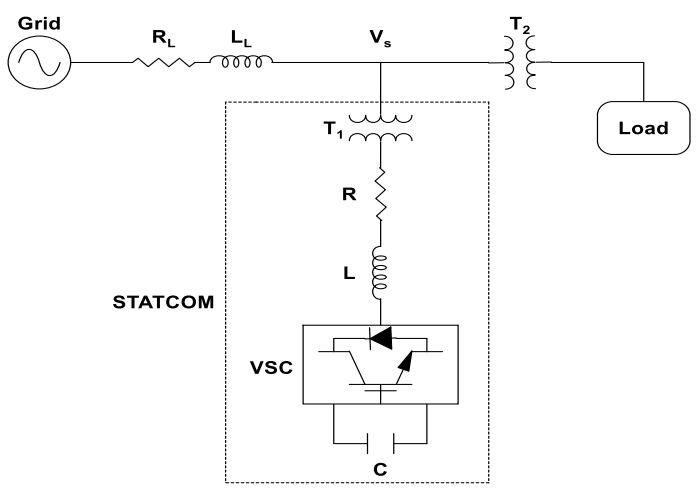

Fig. 1. Static synchronous compensator (STATCOM)

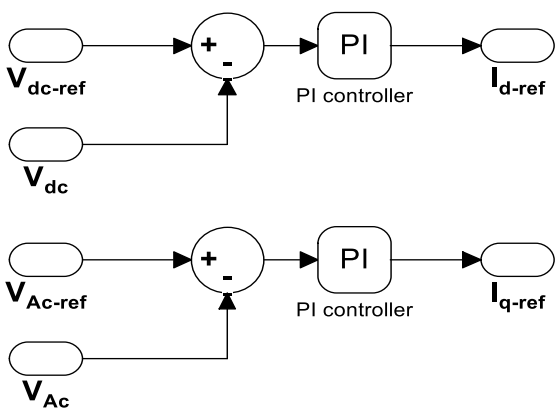

Fig. 2. External control loops

Internal controller or current controller tracks the current references calculated by the external controller. The current controller is the most basic part in the control unit. If the correct operation of the current controller is satisfied, then the grid voltage regulation can be paid. Indeed, this controller part tracks the current references in the fastest time and with zero permanent error. In this paper, a new predictive control method so called

FS-MPC for the internal controller is used [13], [14].

\section{FS-MPC Controller}

The predictive control approach is based on the principle that only a limited number of switching modes may be caused by the converter and the system model can be used to predict the variables for each switching mode. To select an appropriate switching mode, an objective function should be defined [10],[11].All predicted current values of possible switching modes will be evaluated by the objective function and an appropriate switching mode that minimizes the objective function will be selected [7].

\section{A. System Model}

Equations for the dynamics of STATCOM current shown in Fig. 3 can be written in the form of equation (1) for each phase:

$$
\left[\begin{array}{l}
E_{a} \\
E_{b} \\
E_{c}
\end{array}\right]=R \cdot\left[\begin{array}{l}
i_{a} \\
i_{b} \\
i_{c}
\end{array}\right]+L \frac{d}{d t} \cdot\left[\begin{array}{l}
i_{a} \\
i_{b} \\
i_{c}
\end{array}\right]+\left[\begin{array}{l}
v_{a} \\
v_{b} \\
v_{c}
\end{array}\right]
$$

The $R$ and $L$ are resistance and leakage inductance for both filter and isolated transformer. $v_{a, b, c}$ represents the grid phase voltage, $E_{a, b, c}$ is the STATCOM inverter output voltage and $i_{a, b, c}$ is the current vector.

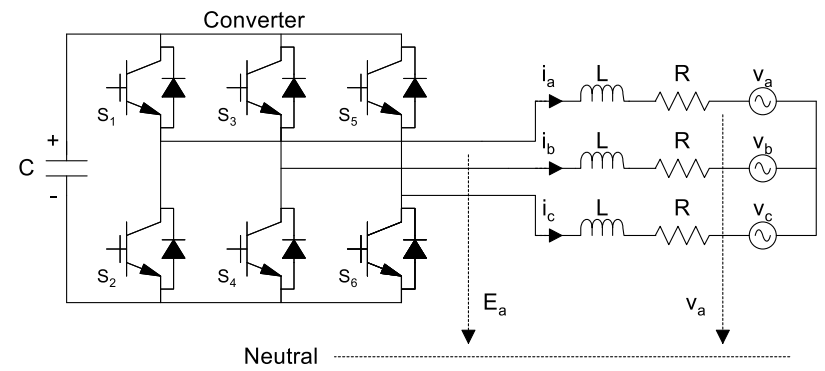

Fig. 3. Schematic diagram of a grid-connected inverter

Using the dq0-transform, the equations of three-phase current is written in the dq frame:

$$
\left[\begin{array}{c}
\frac{d I_{d}}{d t} \\
\frac{d I_{q}}{d t}
\end{array}\right]=\left[\begin{array}{cc}
\frac{-R w_{b}}{L} & w \\
-w & \frac{-R w_{b}}{L}
\end{array}\right] \cdot\left[\begin{array}{l}
I_{d} \\
I_{q}
\end{array}\right]+\frac{w_{b}}{L}\left[\begin{array}{c}
E_{d}-v_{d} \\
E_{q}-v_{q}
\end{array}\right]
$$

where, $w$ and $w_{b}$ are the angular velocity and nominal velocity, respectively.

Now, using a leader Euler approximation for the derivative of the current $\frac{d i}{d t}$ as shown in (3), equation (2) can be converted to a discrete-time model in the form of (4) to predict the current value:

$$
\begin{gathered}
\frac{d i}{d t}=\frac{i(k+1)-i(k)}{T_{s}} \\
\left\{\begin{array}{l}
I_{d}(k+1)=\left(1-\frac{R T w_{b}}{L}\right) I_{d}-\frac{T w_{b}}{L}\left(v_{d}-E_{d}\right)+w T I_{q} \\
I_{q}(k+1)=\left(1-\frac{R T w_{b}}{L}\right) I_{q}-\frac{T w_{b}}{L}\left(v_{q}-E_{q}\right)-w T I_{d}
\end{array}\right.
\end{gathered}
$$

\section{B. Inverter Model}

The power circuit of the STATCOM inverter is shown in Fig. 3. The switching modes of the power switches $S_{a}, S_{b}$ and $S_{c}$ can be zero or one. All of the possible modes together with the output voltage is obtained according to (6) -(7) and shown in Table I. In some previous papers, multilevel converters were proposed because of higher reliability and lower output harmonics [15],[16].

$$
\begin{aligned}
& S_{a}=\left\{\begin{array}{l}
1 \\
0
\end{array}\right. \\
& S_{b}=\left\{\begin{array}{l}
1 \\
0
\end{array}\right. \\
& S_{c}=\left\{\begin{array}{l}
1 \\
0
\end{array}\right.
\end{aligned}
$$




$$
\begin{gathered}
V_{a N}=S_{a} V_{d c} \\
V_{b N}=S_{b} V_{d c} \\
V_{c N}=S_{c} V_{d c} \\
e=\frac{2}{3}\left(0+a V_{b N}+a^{2} V_{c N}\right)
\end{gathered}
$$

\section{Cost Function}

Since the main goal here is to control the current exchanged between the STATCOM and the grid, the main variable of the objective function is the current. Minimizing the error between the measured current and the current reference by the external control loop is the main goal of the current controller.

This objective function is expressed in the dq coordinates and the error between the predicted and the current reference is computed as below:

$$
g=\left|i_{d-r e f}(k+1)-i_{d}(k+1)\right|+\left|i_{q-r e f}(k+1)-i_{q}(k+1)\right|
$$

The FS-MPC controller flowchart is shown in Fig. 4.

Table I - Switching states and voltage vectors

\begin{tabular}{llll}
$\mathrm{S}_{\mathrm{a}}$ & $\mathrm{S}_{\mathrm{b}}$ & $\mathrm{S}_{\mathrm{c}}$ & \multicolumn{1}{l}{ Voltage Vector } \\
\hline 0 & 0 & 0 & $e_{0}=0$ \\
1 & 0 & 0 & $e_{1}=\frac{2}{3} V_{d c}$ \\
1 & 1 & 0 & $e_{2}=\frac{1}{3} V_{d c}+j \frac{\sqrt{3}}{3} V_{d c}$ \\
0 & 1 & 0 & $e_{3}=-\frac{1}{3} V_{d c}+j \frac{\sqrt{3}}{3} V_{d c}$ \\
0 & 1 & 1 & $e_{4}=-\frac{2}{3} V_{d c}$ \\
0 & 0 & 1 & $e_{5}=-\frac{1}{3} V_{d c}-j \frac{\sqrt{3}}{3} V_{d c}$ \\
1 & 0 & 1 & $e_{6}=\frac{1}{3} V_{d c}-j \frac{\sqrt{3}}{3} V_{d c}$ \\
1 & 1 & 1 & $e_{7}=0$
\end{tabular}

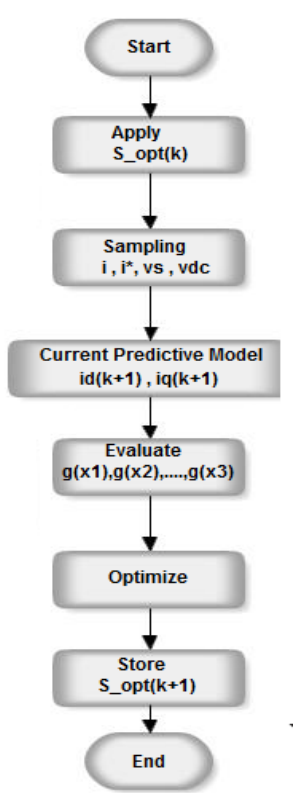

Fig. 4. Flowchart of the FS-MPC controller

\section{Simulation Results}

The STATCOM connected to the $20 \mathrm{kV}$ grid (see Fig. 1) is simulated in MATLAB software. The simulation results with the FS-MPC controller, as well as the conventional PI-PWM controller are discussed in this section. The grid voltage and frequency are considered to $50 \mathrm{~Hz}$ and $20 \mathrm{kV}$, respectively, and STATCOM is connected to it. Full details of the parameters are shown in Tables II and III. As it is clear from Table II, sampling time is $10 \mu \mathrm{Sec}$.

In Figs. 5-6, a general control approach applied to the STATCOM is shown for both methods.

The grid voltage variation in order to study the FS-MPC and PI-PWM methods is shown in Fig. 7. At the second 0.15 , the voltage is dropped to 0.95 p.u. and at the second 0.25 , the voltage is increased to 1.07 p.u.

Table II - System parameters

\begin{tabular}{|c|c|}
\hline Parameter & Value \\
\hline $\mathrm{S}_{\text {Load }}$ & $(3+1.5 \mathrm{j}) \mathrm{MVA}$ \\
\hline $\mathrm{f}$ & $50 \mathrm{~Hz}$ \\
\hline $\mathrm{V}_{\mathrm{s}}$ & $20 \mathrm{kV}$ \\
\hline QstATCOM & $4 \mathrm{MVAr}$ \\
\hline RstATCOM & $0.01 \Omega$ \\
\hline LSTATCOM & $1.3 \mathrm{mH}$ \\
\hline CSTATCOM & $2.8 \mathrm{mF}$ \\
\hline DC link voltage & $3.8 \mathrm{kV}$ \\
\hline $\mathrm{T}_{\mathrm{s}}$ & $10 \mu \mathrm{Sec}$. \\
\hline
\end{tabular}

Table III - Transformer specifications

\begin{tabular}{|c|c|c|}
\hline Transformer & $\mathrm{S}$ & $\mathrm{V}_{1} / \mathrm{V}_{2}$ \\
\hline $\mathrm{T}_{1}$ & $4 \mathrm{MVAr}$ & $20 / 1.8(\mathrm{kV})$ \\
\hline $\mathrm{T}_{2}$ & $6 \mathrm{MVAr}$ & $20 / 0.4(\mathrm{kV})$ \\
\hline
\end{tabular}

In Fig. 8, the current exchanged between STATCOM and the grid is shown. In fact, in the time interval 0.15 to 0.2 Sec. and time interval 0.25 to $0.3 \mathrm{Sec}$. in which the changes in voltage are occurred in the grid voltage, the current exchanged between the grid and STATCOM is made. As seen in Fig. 8, the amount of current ripple at the FS-MPC method is less than the one in PI-PWM.

In Fig. 9 and Table IV, the current ripple and current THD are known. It shows a minimized distortion and THD of the STATCOM current in FS-MPC compared to PI-PWM control method.

\section{A. Reference Tracking}

In general, tracking the current references made by the external PI controllers indicates the correct controller performance. The external PI controller coefficients are given in Table $\mathrm{V}$ and also Pi-PWM controller gains are given in Table VI. 


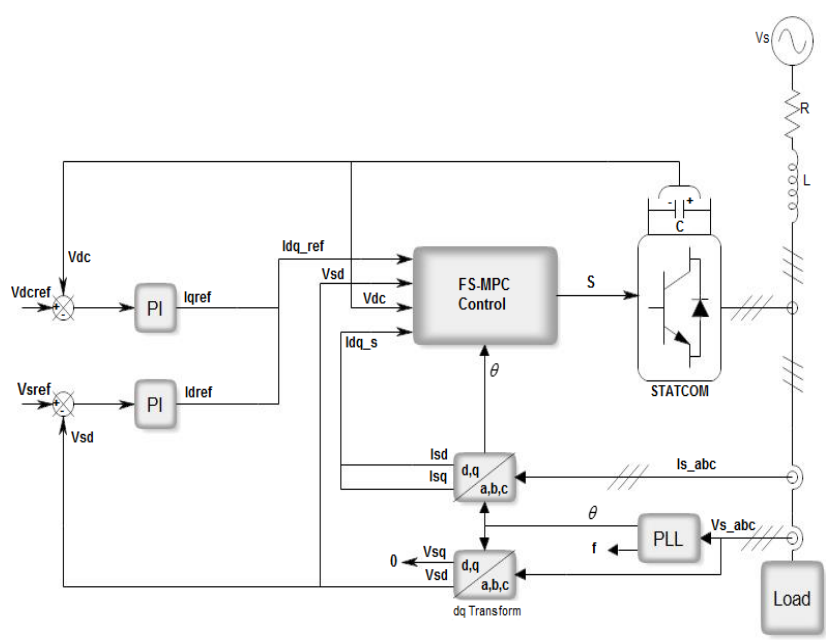

Fig. 5. STATCOM FS-MPC controller

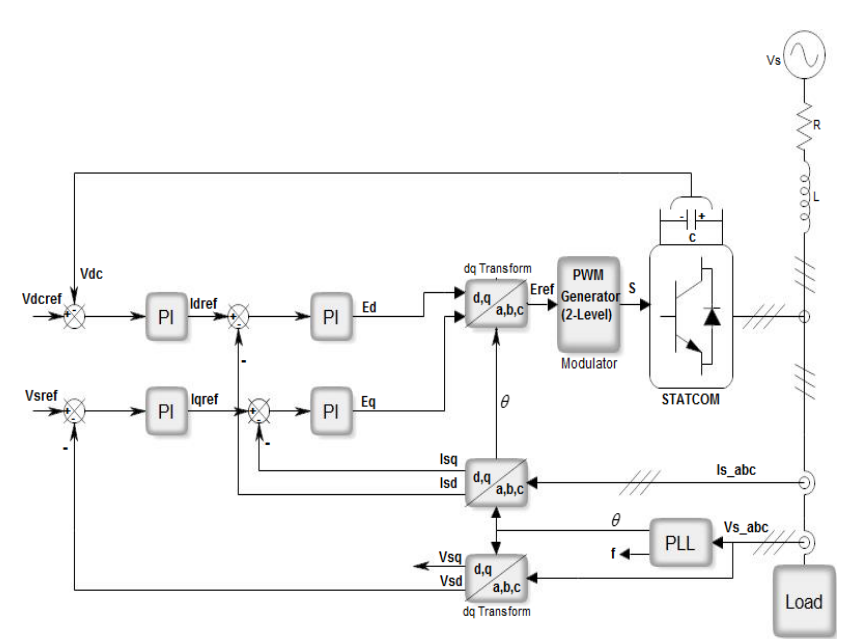

Fig. 6. STATCOM PI-PWM controller

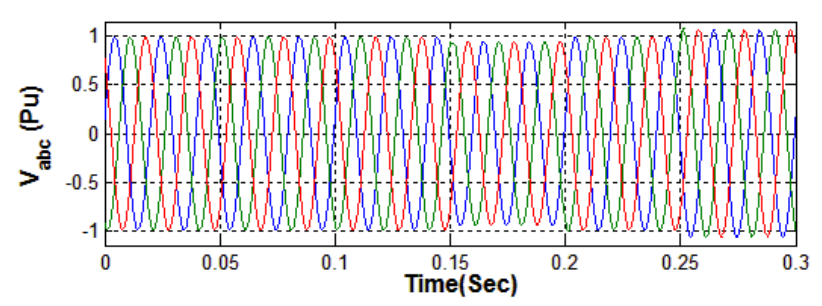

Fig. 7. Three-phase ac output voltage (p.u.)

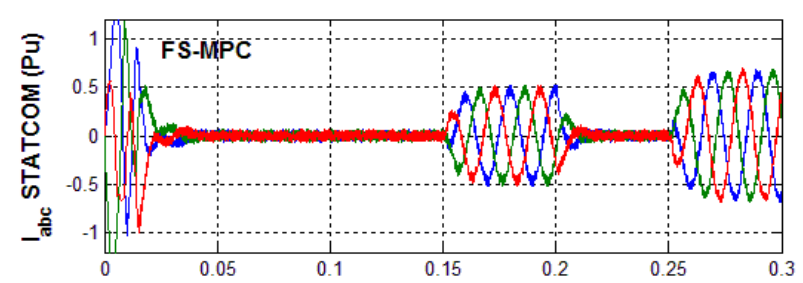

(a)

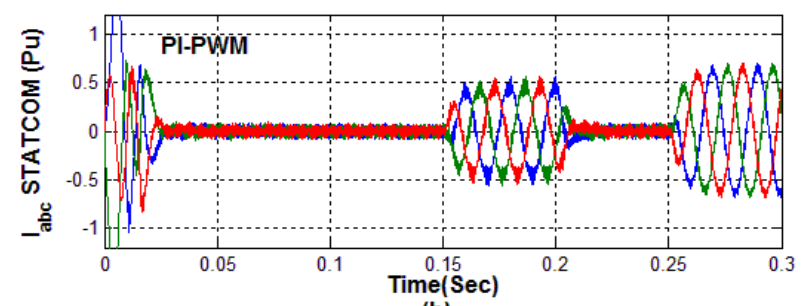

(b)

Fig. 8. Current exchanged between the grid and STATCOM
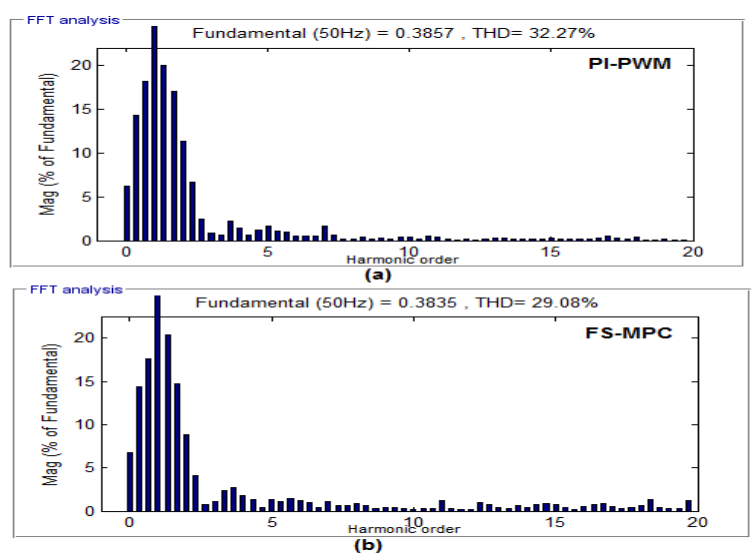

Fig. 9. THD of STATCOM Current

Table IV - Transformer specifications

\begin{tabular}{|c|c|}
\hline THD Current (PI-PWM) & THD Current (FS-MPC) \\
\hline $32.27 \%$ & $29.08 \%$ \\
\hline
\end{tabular}

Table V - External controller gains

\begin{tabular}{|c|c|c|}
\hline PI controller Input & $\mathrm{K}_{\mathrm{i}}$ & $\mathrm{K}_{\mathrm{p}}$ \\
\hline DC-link voltage & 0.1 & 0.001 \\
\hline Grid Voltage & 1200 & 0.2 \\
\hline
\end{tabular}

Table VI- PI-PWM controller gains

\begin{tabular}{|c|c|c|}
\hline PI controller Input & $\mathrm{K}_{\mathrm{i}}$ & $\mathrm{K}_{\mathrm{p}}$ \\
\hline $\mathrm{I}_{\mathrm{d}-\mathrm{ref}}$ & 120 & 2.5 \\
\hline $\mathrm{I}_{\mathrm{q}-\text {-ref }}$ & 120 & 2.5 \\
\hline
\end{tabular}

Fig.10 shows the tracking of the q- current reference for both controllers, which is proportional to the amount of reactive power exchanged with the grid for the voltage regulation.

Fig. 11 shows a good tracking of the active current reference. As it can be seen the active current fluctuates on zero. Because the STATCOM injects only the reactive power into the grid and no active power is injected.

Only a small amount of the active power is absorbed from the grid to compensate the power losses and to adjust the DC link voltage. Fig. 12 shows that the DC link voltage is nearly fixed on $3600 \mathrm{~V}$ for both controllers.

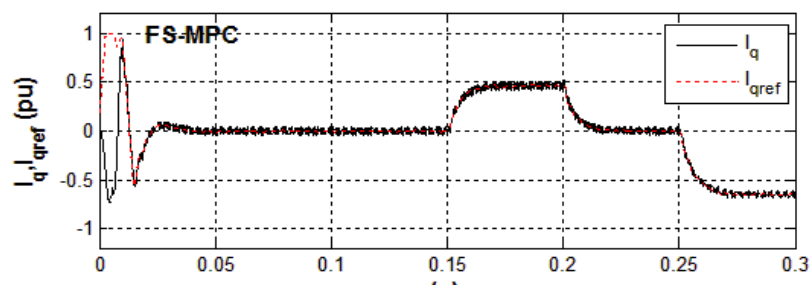

(a)

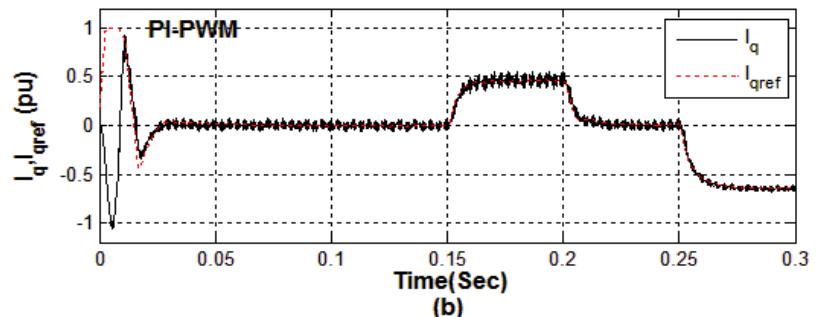

Fig. 10. Tracking of the output reactive current in q-axis 


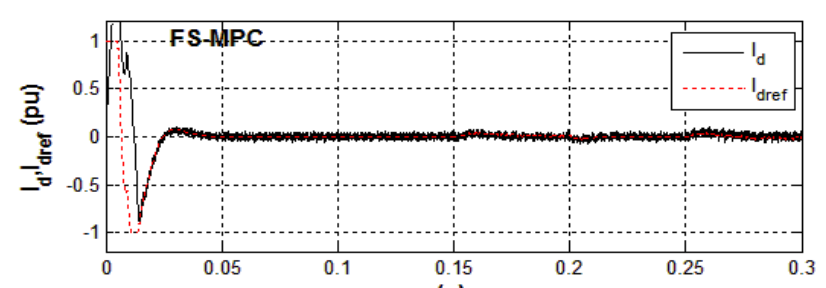

(a)

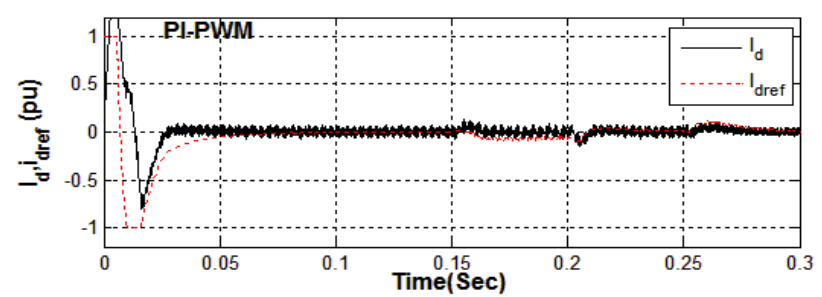

(b)

Fig. 11. Tracking of the output active current in d-axis

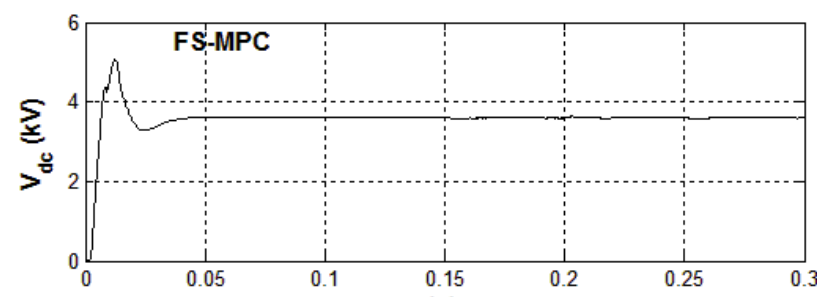

(a)

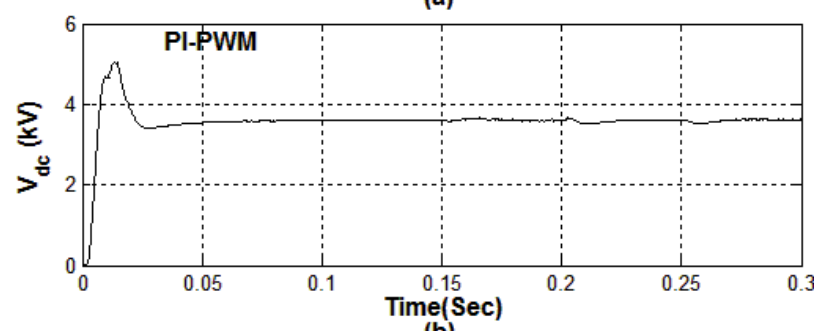

(b)

Fig. 12. DC link voltage

\section{B. Exchanged Active and Reactive Power}

As mentioned, the STATCOM just injects the reactive power to the grid and no active power is exchanged with the grid and only small amounts of the active power is absorbed from the grid to compensate the power losses. If it is a need to inject the active power to the grid, then a power storage (such as a battery) should be placed in the DC link.

In Fig. 12, the power (active and reactive) exchanged between STATCOM and grid is well shown. As seen in Fig. 12, at the interval 0.15 to $0.2 \mathrm{Sec}$., STATCOM has acted as a capacitive load and about 1.8 MVAr reactive power for the voltage regulation is injected into the grid. But at the interval 0.25 to $0.3 \mathrm{Sec}$. since the grid voltage is increased, STATCOM has acted as an inductive load and 2 MVAr reactive power is absorbed from the grid. However, as it can be seen in Fig. 12, the voltage does not change at the interval 0.2 to $0.25 \mathrm{Sec}$. and is fixed on 1 p.u.; therefore, no reactive power is exchanged between the grid and STATCOM.

It can also be seen in Fig. 13; no active power is exchanged between the grid and STATCOM and only small amounts of the active power is absorbed from the grid which is dissipated on the switches and DC link.

\section{Inverter and Grid Voltage}

In Fig. 14, the output phase voltage of the STATCOM inverter is shown. As it can be seen, the voltage levels are generally divided into 5 levels equal to $0,-\frac{V_{d c}}{3}, \frac{V_{d c}}{3}$, $-\frac{2 V_{d c}}{3}, \frac{2 V_{d c}}{3}$. As it is indicated in Fig. 13, in the FS-MPC controller since it does not impose any pattern on the switching signal, the optimized switching state can be maintained by different sampling periods. As a result, the

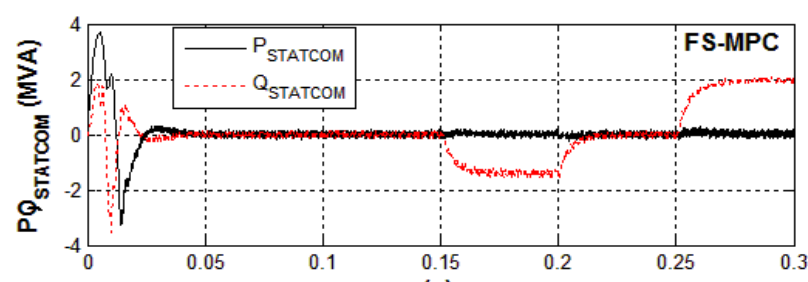

(a)

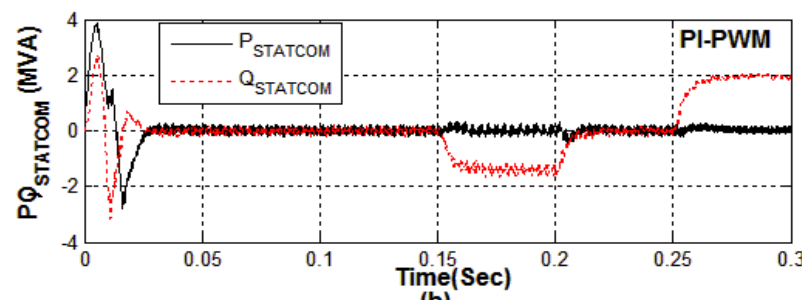

(b)

Fig. 13. Exchanged power between the grid and STATCOM

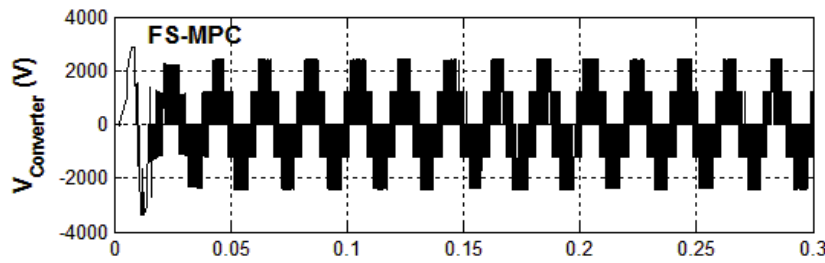

(a)

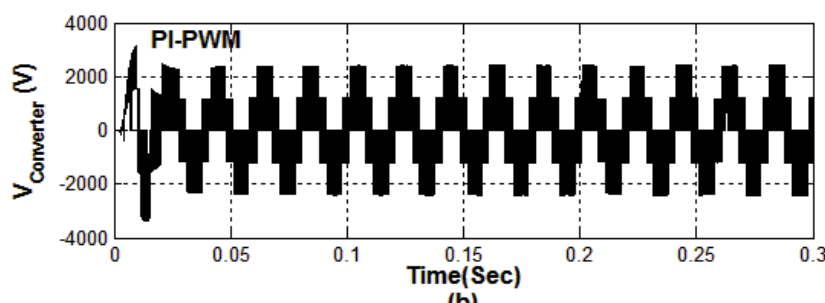

(b)

Fig. 14. Multilevel STATCOM phase voltage

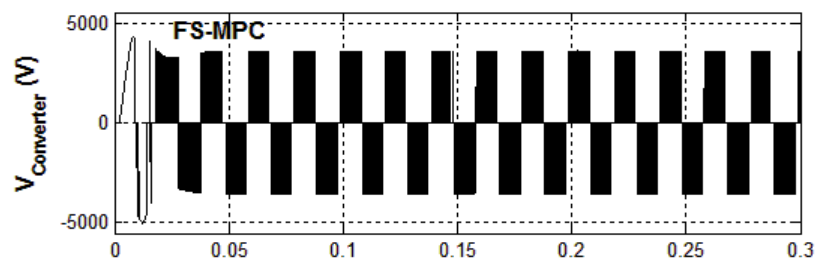

(a)

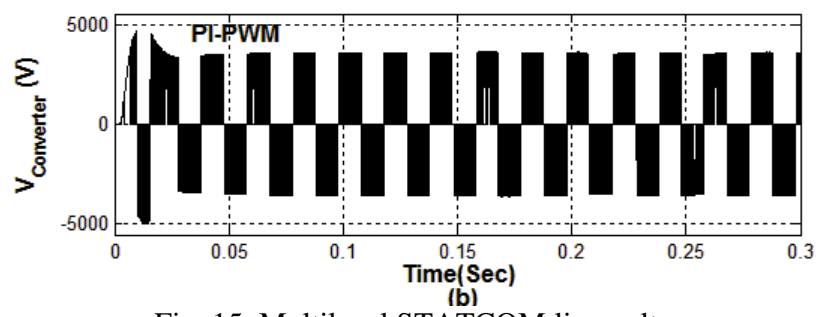

Fig. 15. Multilevel STATCOM line voltage 
switching frequency is variable. But in the conventional PI controller with PWM the switching frequency is fixed (here equal to $1.4 \mathrm{kHz}$ ).

In Fig. 15, the output line voltage of the STATCOM is shown in which the voltage levels are $-V_{d c}, 0, V_{d c}$.

In Fig. 16(a) the voltage regulated by the FS-MPC controller and in Fig. 16(b) the voltage regulated by the PIPWM controller are shown.

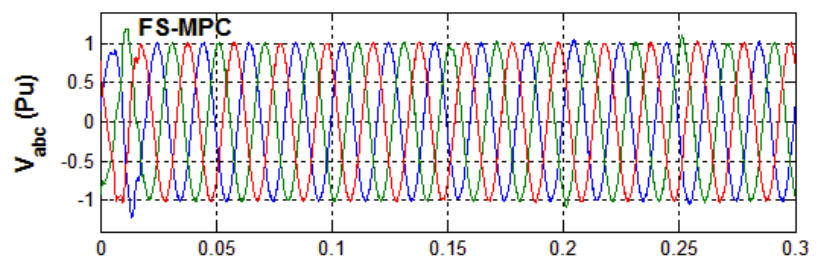

(a)

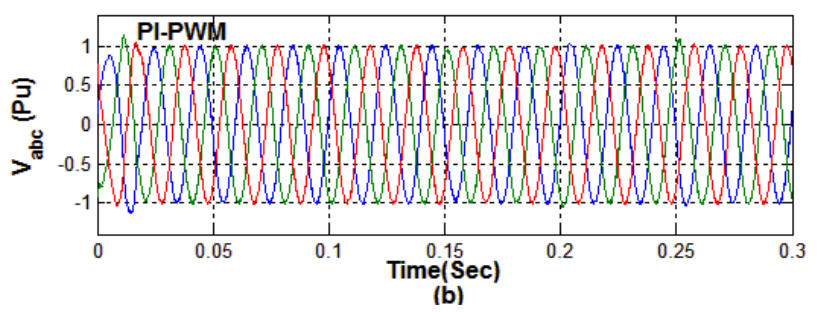

Fig. 16. Three-phase ac output voltage

\section{Conclusion}

In this paper, a predictive model control type i.e. FS-MPC is used to regulate the grid voltage via STATCOM. This method is based on the use of the system model to predict the behavior of the output current in STATCOM by defining a cost function that leads to the selection of appropriate switching states for the forthcoming periods. The conventional PI-PWM method is also simulated in order to be compare with the FS-MPC. It is found that the FS-MPC method generally produces lower current ripple than the PI-PWM. Also, since there is neither a PI controller (and as a result no need to set the PI gains) in the FS-MPC nor a modulator, it would be easier to implement compared to the PI-PWM method. In the FSMPC, however, various terms and variables can also be added to the cost function.

In the meantime, the switching frequency is variable for the FS-PWM, while it is fixed for the PI-PWM due to the employed modulator. However, according to the simulations, both controllers have good performance against voltage changes. Therefore, with regards to the operation condition, one can decide which of the two controllers to be applied in practice.

\section{References}

[1] shahnia, F., Rajakaruna, S., \& Ghosh, Static Compensators (STATCOMS) in power systems, Springer, Singapore (2015).
[2] Rahimzadeh, S., Bina, M.T. , "Planning required for FACTS devices to improve the steady state efficiency of restructured power systems: A review ," International Review of Electrical Engineering 2009, Vol.4, pp 417-424.

[3] Xu, Y., \& Li, F, "Adaptive PI control of STATCOM for voltage regulation", IEEE Transactions on Power Delivery 2014, Vol. 29(3), pp 1002-1011.

[4] Dinesh L, Sesham H, Manoj V, "Simulation of D-Statcom with hysteresis current controller for harmonic reduction", In: Proceedings of the international conference on emerging trends in electrical engineering and energy management (ICETEEEM) 2012.

[5] Chandrakar, V. K., \& Kothari, "A. G Fuzzy-based static synchronous Compensator (STATCOM) for improving transient stability performance", International Journal of Energy Technology and Policy 2007, Vol. 5(6), pp 692.

[6] Mohagheghi, S., Venayagamoorthy, G. K., \& Harley, R. G., "Adaptive critic design based Neuro-Fuzzy controller for a static Compensator in a Multimachine power system", IEEE Transactions on Power Systems 2007, Vol. 21(4), pp 1744-1754. [7] D P. Cort'es, M. P. Kazmierkowski, R. M. Kennel, D. E. Quevedo, and J. Rodr'1guez, "Predictive control in power electronics and drives," IEEE Transactions on Industrial Electronics 2008, Vol. 55, no. 12.

[8] Venkata Yaramasu, Marco Rivera., Mehdi Narimani, Bin Wu "Model Predictive Approach for a Simple and Effective Load Voltage Control of Four-Leg Inverter with an Output LC Filter," Industrial Electronics, IEEE Transactions, October 2014, Vol.10, pp 5259-5270.

[9] S.-M. Yang and C.-H. Lee, "A deadbeat current controller for field oriented induction motor drives," IEEE Trans. Power Electron, Sep. 2002, Vol. 17, no. 5, pp. 772-778.

[10] J. Rodriguez, M. Kazmierkowski, J. Espinoza, P. Zanchetta, H, "Abu-Rub, H. Young, and C. Rojas, "State of the art of finite control set model predictive control in power electronics," Industrial Informatics, IEEETrans, 2013, Vol. 9, no. 2, pp. $1003-$ 1016.

[11] R. Aguilera, P. Lezana, and D. Quevedo, "Finite-controlset model predictive control with improved steady state performance," Industrial Informatics, IEEE Transactions on, 2013, vol. 9, no. 2, pp. 658-667.

[12] Rahimzadeh, S., Bina, M.T., Viki, A.H. , "Steady state model of STATCOM and SSSC using averaging technique," International Review of Electrical Engineering 2009,Vol.4, Issue 6, pp.1391-1403.

[13] S. Mariethoz and M. Morari, "Explicit model-predictive control of a PWM inverter with an LCL filter," IEEE Transactions on Industrial Electronics February 2009, Vol. 56, no. 2, pp. 389-399.

[14] Tarisciotti L, Zanchetta P, Watson A, Bifaretti S, Clare JC, "Modulated model predictive control for a seven-level cascaded H-bridge back-to-back converter,”. IEEE Trans Ind Electron61, pp.5375-5383.

[15] Mojibian, M.J. , Bina, M.T. , "Classification of multilevel converters with a modular reduced structure: Implementing a prominent 31-level $5 \mathrm{kVA}$ class B converter," IET Power Electronics 2015,Vol. 8, pp. 20-32.

[16] Pirouz, H.M., Bina, M.T, "Modular multilevel converter based STATCOM topology suitable for medium-voltage unbalanced systems," Journal of Power Electronics 2010, Vol.10 (5), pp. 572-578. 